\title{
Linear morphea involving the underlying muscle
}

\author{
Naoki Yamamoto ${ }^{1}$ [ $\cdot$ Akihiro Dejima $^{1} \cdot$ Kenkou Hasatani $^{1}$
}

Received: 9 April 2021 / Revised: 12 May 2021 / Accepted: 22 May 2021 / Published online: 27 May 2021

(c) International League of Associations for Rheumatology (ILAR) 2021

\section{Presentation}

A 62-year-old woman with hypothyroidism and diabetes visited our hospital with bilateral stiffness and swelling beginning from the forearms and progressing to the fingers. Her symptoms appeared 1 year prior and gradually deteriorated. On physical examination, both forearms showed stiffness and swelling with well-circumscribed glossy skin (Fig. 1a). However, there was no evidence of Raynaud's phenomenon, critical digital ischemia, skin thickening except for upper limbs, dysphagia, dyspnea, or other organ involvement. The results of serum examinations were as follows: creatine kinase (CK), 429 IU/L (normal: 41-153) (CK-MB 27\%, CK-MM 73\%); aldolase, 7.5 U/L (normal: 2.7-5.9); free-T3, $3.05 \mathrm{pg} / \mathrm{mL}$ (normal: 2.20-4.10); freeT4, $0.68 \mathrm{ng} / \mathrm{dL}$ (normal: 0.72-1.52); TSH, $7.356 \mu \mathrm{IU} / \mathrm{mL}$ (normal: 0.400-3.700); random blood glucose, $191 \mathrm{mg} /$ dL (normal: 70-200); and hemoglobinA1c, 6.8\% (normal: 4.9-6.0). Antinuclear antibody (ANA) was positive at a titer of 1:80 with homogenous pattern (normal: $<1: 40$ ) and anti-single-stranded (ss) DNA immunoglobulin $\mathrm{G}$ antibody tested positive at $40.8 \mathrm{AU} / \mathrm{mL}$ (normal: <25). The other antibodies including anti-double-stranded DNA antibody, anti-ribonucleoprotein antibody, anti-topoisomerase I antibody, anti-centromere antibody, anti-RNA polymerase III antibody, anti-aminoacyl tRNA synthetase antibodies, anti-Mi-2 antibody, anti-MDA5 antibody, and anti-TIF1 gamma antibody were negative. Contrast fat-suppressed T1-weighted magnetic resonance imaging (MRI) showed diffuse enhancement of the extensor muscle group, flexor digitorum profundus muscle, and palmaris longus muscle of the right forearm without fasciitis (Fig. 1b). En bloc biopsy of the right forearm revealed increased and thickened collagen bundles in the dermis, and muscle bundles showed

Naoki Yamamoto

ny0724jp@gmail.com

1 Department of Internal Medicine, Suzu General Hospital, 1-1, Nonoe, Suzu, Ishikawa 927-1213, Japan lymphocytic infiltration between the bundles with myonecrosis. The deep fascia did not reveal eosinophilic infiltrates or any inflammation (Fig. 1c, d). She was diagnosed with linear morphea and received combined prednisolone (PSL) $40 \mathrm{mg}$ per day $(0.8 \mathrm{mg} / \mathrm{kg})$ and methotrexate (MTX) $8 \mathrm{mg}$ per week, resulting in gradual improvement of stiffness and swelling. Four weeks later, CK and anti-ss DNA were decreased to $57 \mathrm{IU} / \mathrm{L}$ and $11.9 \mathrm{AU} / \mathrm{mL}$, respectively, but the weak enhancement of muscles persisted on MRI. Twelve weeks later, PSL was tapered to $10 \mathrm{mg}$ per day, and MTX was increased to $12 \mathrm{mg}$ per week.

\section{Discussion}

Morphea, or localized scleroderma, is a rare inflammatory disease characterized by well-circumscribed sclerotic skin changes. Morphea shows a wide spectrum of clinical manifestations, ranging from involvement of the skin and subcutaneous tissue to the musculoskeletal system. Linear morphea presents as band-like cutaneous sclerosis with joint contractures and muscle weakness. Although no specific antibodies are detected in the morphea, ANA is positive in $34 \%$, with a speckled pattern as the most common pattern (81\%) on immunofluorescence [1]. However, a homogenous pattern was the predominant $(70 \%)$ in mestizo Mexican children with morphea [2]. Anti-ss DNA antibody and anti-histone antibody are associated with more extensive skin diseases with joint contractures and reflect disease activity [3]. MRI is recommended for the evaluation of musculoskeletal involvement. En bloc biopsy is useful in detecting the depth of inflammation and differentiating eosinophilic fasciitis, lichen sclerosus et atrophicus, sclerosing panniculitis, and scleromyxedema. Topical corticosteroids and phototherapy are considered for superficial skin lesions, but systemic PSL and MTX treatment should be initiated for deep involvement [4]. We should be familiar with the correlation between the skin and musculoskeletal system. 
Figure 1 a Well-circumscribed glossy skin in the left forearm. b Diffuse enhancement of the extensor muscle group, flexor digitorum profundus muscle, and palmaris longus muscle of the right forearm on contrast fat-suppressed T1-weighted magnetic resonance imaging. c Thickened and increased collagen bundles in the dermis. d Lymphocyte infiltration between the muscle bundles with myonecrosis.

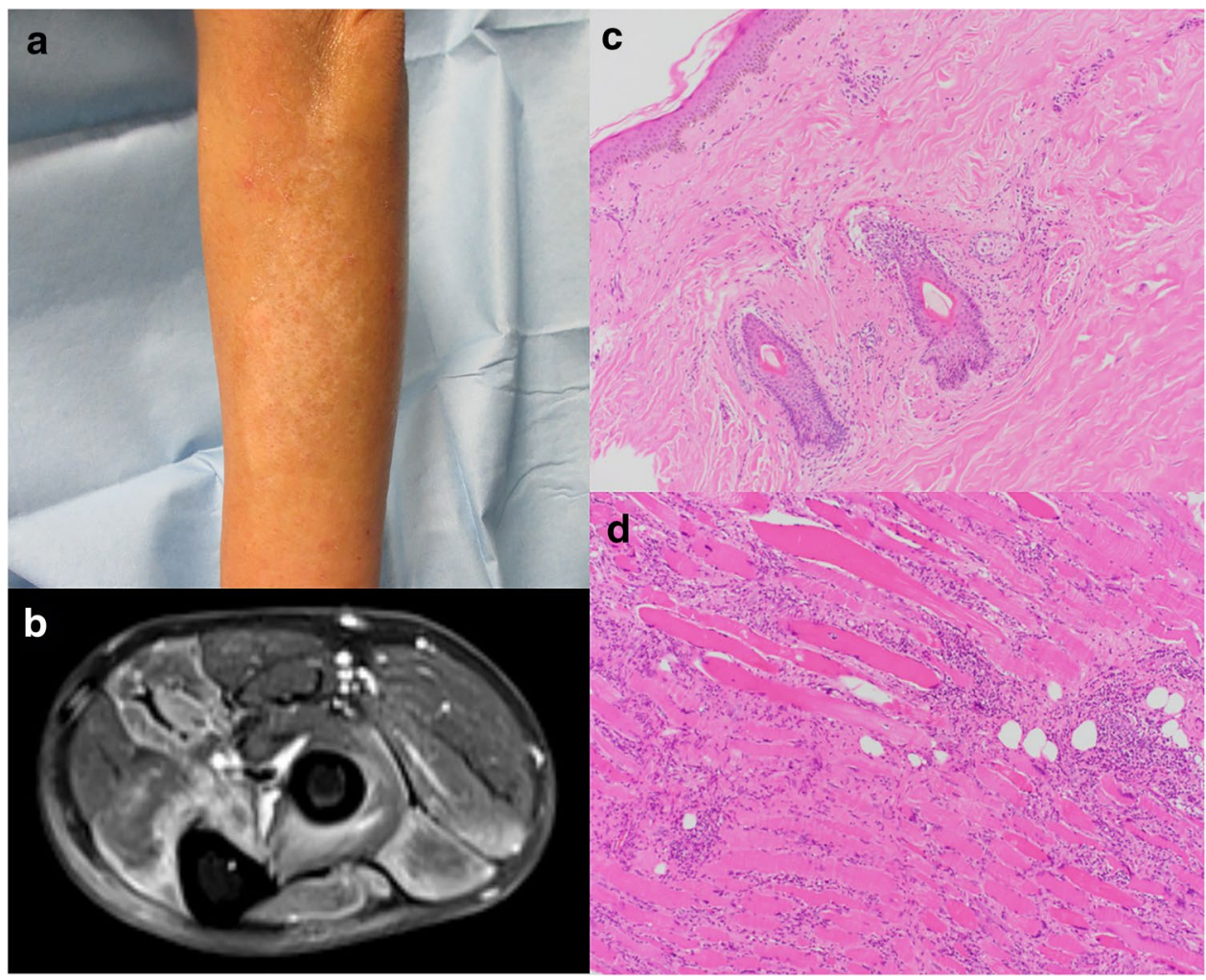

\section{Declarations}

Consent for publication We obtained written informed consent from the patient for publication.

Disclosures None.

\section{References}

1. Dharamsi JW, Victor S, Aguwa N, Ahn C, Arnett F, Mayes MD, Jacobe H (2013) Morphea in adults and children cohort III: nested case-control study-the clinical significance of autoantibodies in morphea. JAMA Dermatol 149:1159-1165. https://doi.org/10. 1001/jamadermatol.2013.4207

2. Guevara-Gutiérrez E, Yinh-Lao J, García-Gutiérrez P, TlacuiloParra A (2010) Frequency of antinuclear antibodies in mestizo
Mexican children with morphea. Clin Rheumatol 29:1055-1059. https://doi.org/10.1007/s10067-010-1515-2

3. Arkachaisri T, Fertig N, Pino S, Medsger TA Jr (2008) Serum autoantibodies and their clinical associations in patients with childhood- and adult-onset linear scleroderma A single-center study. J Rheumatol 35:2439-2444. https://doi.org/10.3899/ jrheum.080098

4. Torok KS, Arkachaisri T (2012) Methotrexate and corticosteroids in the treatment of localized scleroderma: a standardized prospective longitudinal single-center study. J Rheumatol 39:286-294. https://doi.org/10.3899/jrheum.110210

Publisher's note Springer Nature remains neutral with regard to jurisdictional claims in published maps and institutional affiliations. 